\title{
コヒーレントビーム干渉パターンのデザインと 金ナノウィスカーマトリクス構造の作製
}

\author{
中田 芳樹，松葉 良生，村川 惠一，宮永 憲明 \\ 大阪大学レーザーエネルギー学研究センター（５565-0871 大阪府吹田市山田丘2-6）
}

\section{Designing of Interference Pattern Using Coherent Beams and Fabrication of Gold Nanowhisker Arrayed in Matrix}

\author{
Yoshiki NAKATA, Yoshiki MATSUBA, Keiichi MURAKAWA, and Noriaki MIYANAGA \\ Institute of Laser Engineering, Osaka University, 2-6 Yamadaoka, Suita, Osaka 565-0871
}

(Received July 18, 2013)

\begin{abstract}
An interference pattern of ultra-short pulse laser can be transcribed to material surface, and great number of unit structures in matrix can be generated. In this paper, a variety of unit patterns are summarized in the case of four and six beam correlation. The patterns can be controlled by phase and amplitude variation between beams, and with ratio between processing fluence and ablation threshold. In addition, interference patterns with concurrent irradiation of fundamental and second-harmonic generation (SHG), named "mode-locked interference" are shown. "Au nanowhisker", which is a 3D nanostructure fabricated by SLS (Solid-Liquid-Solid) process induced by interfering femtosecond laser processing, was observed by TEM (transmission electron microscope).
\end{abstract}

Key Words: Femtosecond laser processing, Interference, SHG, Solid-liquid-solid process, Metamaterial

\section{1. はじめに}

微細な周期構造を固体表面や内部に修飾した構造には 種々の応用が有る。例えばブラッググレーティング1)や DFBレーザー ${ }^{2)}$ などの一次元周期構造，ホログラムなど の二次元構造 ${ }^{3}$ などである。一方我々は干渉した超短パ ルスレーザーを利用し, 波長オーダーサイズの単位構造 が一次元 ·二次元周期配列した構造を一括作製する研究 を進めている ${ }^{5-13)}$ ，例えば金属薄膜ターゲットでは，開 口が波長オーダーサイズのMHA(Metal Hole Array)など の2次元メタマテリアル4 がシングルショットで加工で き5-7), さらにSolid-Liquid-Solid (SLS) プロセス ${ }^{12)}$ を誘起 することで3次元金属ナノ周期構造が作製出来る ${ }^{5,8-12)}$. 本手法は，周期ナノ構造を作製出来る新しい手法として 注目されている.

本論文では，4光束及び6光束干渉におけるビーム間の 位相及び強度変調による干渉パターンの変化を調べ，さ らに加工しきい值と加工フルエンスの関係によるデザイ ン変化を明らかにし，メタマテリアルに代表されるプラ ズモニクス応用への有用性を明らかにする ${ }^{10,13,14)}$ 。さら に，半波長を持つSHG (Second-Harmonic Generation) と基 本波を同時に干渉させる“mode-locked interference” (モー ド同期干渉)という新しい手法を提案する.

一方，金属の流体的挙動によるSLSプロセスを用いる 事で3次元ナノ構造が作製できる，本論文では，SLSプ
ロセスで作製されたナノウイスカーの形状及び結晶構造 をTEMで詳細に調べた結果を紹介する。

$$
\text { 2. 干渉パターンのシミュレーション }
$$

\section{1 干渉パターンのシミュレーション理論}

干渉パターンは以下の式で表される. $k$ : 波数, $\omega$ : 角周波数, $\varphi_{n}$ : ビーム間の位相, $E_{n 0}$ : 電界強度であ る.

$$
\begin{aligned}
& I(x, y, z)=\int\left|\sum_{n=1,2, \ldots}^{N} E_{n}\left(x, y, z, \theta_{\mathrm{int}, n}, \theta_{\mathrm{rot}, n}, \varphi_{n}, t\right)\right|^{2} d t \\
& E_{n}\left(x, y, z, \theta_{\mathrm{int}, n}, \theta_{\mathrm{rot}, n}, \varphi_{n}, t\right)=E_{n 0} \cos \left(k \cos \theta_{\mathrm{int}, n} \times\right. \\
& \left.z+k \sin \theta_{\mathrm{int}, n} \times\left(-x \cos \theta_{\mathrm{rot}, n}-y \sin \theta_{\mathrm{int}, n}\right)-\omega t+\varphi_{n}\right)
\end{aligned}
$$

以下の小節では，4ビームまたは6ビーム干渉，基本波
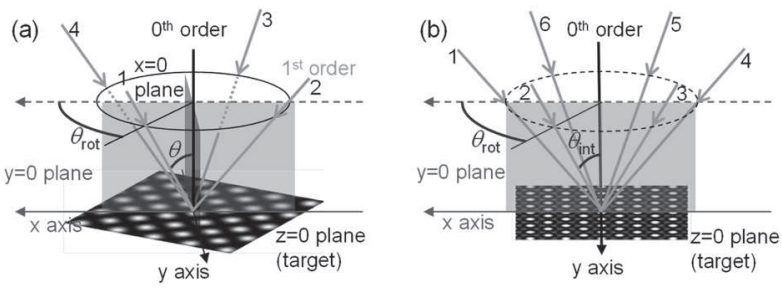

Fig. 1 bird's eye view of (a) four beam correlation and (b) six beam correlation. 
とSHGのそれぞれ4ビームが干渉する場合に分けて述べ る. Fig. 1は4ビーム干渉及び6ビーム干渉の模式図であ る。干渉角は4 ビーム干渉及び6ビーム干渉が $\theta_{i n t}=14.6^{\circ}$, 2波長干渉では $20.1^{\circ}$ とし, 波長を $\lambda_{\text {fundamental }}=785 \mathrm{~nm}$ に設 定した．膨大な干渉条件の組み合わせの中から一部を ピックアップしており, 詳細は論文に譲る ${ }^{13,14)}$.

\subsection{4ビーム干渉における干渉パターン}

Fig. 2に計算結果を示す. (a)から (e)の干渉条件毎に 上から干渉条件の説明図, 干渉パターン，しきい值パ ターン(フルエンスによる加工形状の変化)である. 図の 右下は位相差・強度比の表記方法, 及びしきい值パター ンを表す。 $F_{\max }$ は干渉パターンにおいて一番高いフルエ ンスであり，その小数倍を加工しきい值に設定した場 合, 灰色の部分が加工され, 黒い部分が加工されない事 を意味する。

まず，位相・光強度全て均一の場合をFig. 2 (a) に示 す.フルエンスが高いスポットがマトリクス状に並んで (a)
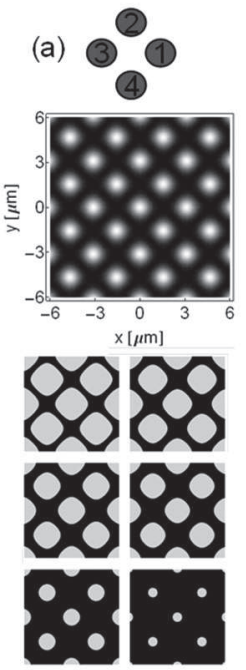

(d)
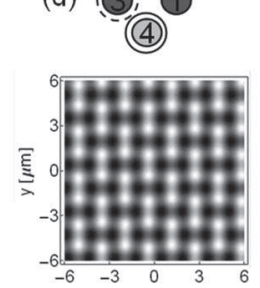

$x[\mu \mathrm{m}]$

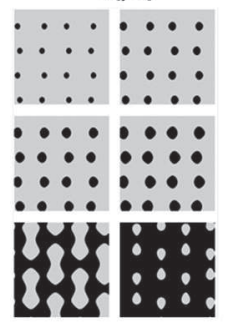

(b)
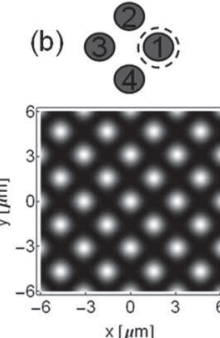

$x[\mu \mathrm{m}]$

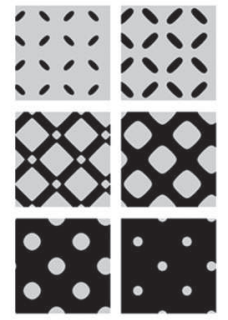

(e)
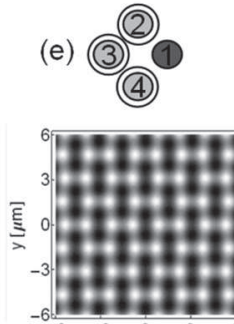

$x[\mu \mathrm{m}]$

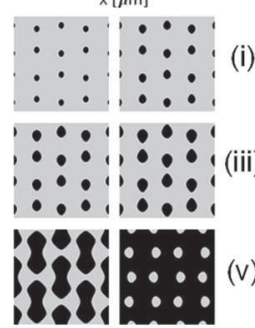

(i) $<0.05$
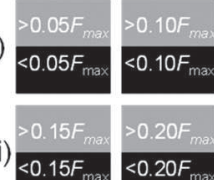

$0.15 F_{m}$
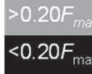

$<0.50 F<0.80 F$
$>0.50 F_{\text {max }}>0.80 F_{m}$

Fig. 2 Interference patterns of four beams at different parameters and ablation thresholds. Illustration on each interference pattern explains phase and amplitude shift parameters, based on the rule shown in right lower-middle sketch. Right low inset explains threshold pattern to its peak fluence.
いることが分かる.フルエンスが比較的低いFig. 2 (a) (vi)の場合は径の小さなメッシュになり，フルエンスと 共にメッシュ径が大きくなる。金属薄膜を素材に用いる 場合は金属メッシュが形成され，これは異常透過を示す メタマテリアルにおけるMHA構造に相当する4)

次に, 一本のビームに位相 $\varphi_{1}=\pi / 2, \pi$ を加えた場合を それぞれFig. 2 (b)，（c）に示す. Fig. 2 (b)の場合ピーク 間に別の小さなピークが現れており，Fig. 2 (c) では全 てのピーク強度が同じになる。この時ピークの数密度は 位相差が無いFig. 2 (a) 場合の倍になっている. Fig. 2 (c) (v)ではチェック形状のメタマテリアルにな $3^{15)}$.

次に, ビーム間の強度と位相を変調した場合の干渉パ ターンをFig. 2 (d) と (e)に示す。 それぞれ (v)を見ると， ピーナッツ状の高/低フルエンス部分が配列する。ここ で，ロッドが配列した構造が負の屈折率を持つメタマテ リアルとして広く用いられており, 直接加工では前者, 光感光などを用いる場合は後者が利用出来る.

4光束干渉におけるパラメーターの組み合わせは膨大 であるが，21のパターンにカテゴライズされる事が解っ ている13).

\subsection{6ビーム干渉における干渉パターン}

強度・位相シフトの表記，しきい值パターンの配列は 4ビームの場合と同じで有るが，4ビームの「光強度」では 無く「電界強度」の比を $E=1.0,0.5,0.0$ で変調してい る.

まず位相・強度全て均一の場合をFig. 3 (a)に示す. 六方格子上にピークが並んでいる。フルエンスが高い Fig. 3 (a) (i)（ii)では, リング・ナット状の領域が残る. 次に, 一本に位相 $\varphi_{1}=\pi$ を加えた場合の干渉パターンを Fig. 3 (b)に示す. 6光束にもかかわらず六方格子でない 配列が現れている. Fig. 3 (b) (i) - (iv)にみられるライン とドットが配列する構造は, 負の屈折率を示すメタマテ リアルとして知られている ${ }^{16)}$. Fig. 3 (c) (i)ではDouble SRR (Split-Ring Resonator)が形成されており，偏光のコ ントロールに有用である ${ }^{17)}$. Fig. 3 (d) は6光束から4光束 を選んだ場合であるが，Fig. 20場合と $\theta_{\text {rot }, n}$ が異なる。し きい值毎に様々な太さのクロスが形成されており，これ らも代表的なメタマテリアルである ${ }^{18)}$. Fig. 3 (e) (ii) (iii) はSingle SRR (Split-Ring Resonator)であり, 非線形性 の発現などで多用される ${ }^{19)}$. Fig. 3 (f) は3本のビームが 対等に干渉しており，(i)，（ii）では三角形がコンタクト して配列した形状が作製される。これは“Bowtie”と呼ば れ，三角形の間隙で巨大な電界集中が起きる形状である ことが知られている. Bowtieが2次元配列した構造をシ ングルショット加工出来れば, SERS (Surface-Enhanced Raman Scattering)における基板として非常に有用である と考えられる ${ }^{20)}$.

6光束干渉におけるパラメーターの組み合わせは膨大 であるが，32のパターンにカテゴライズされる事が解っ ている14). 

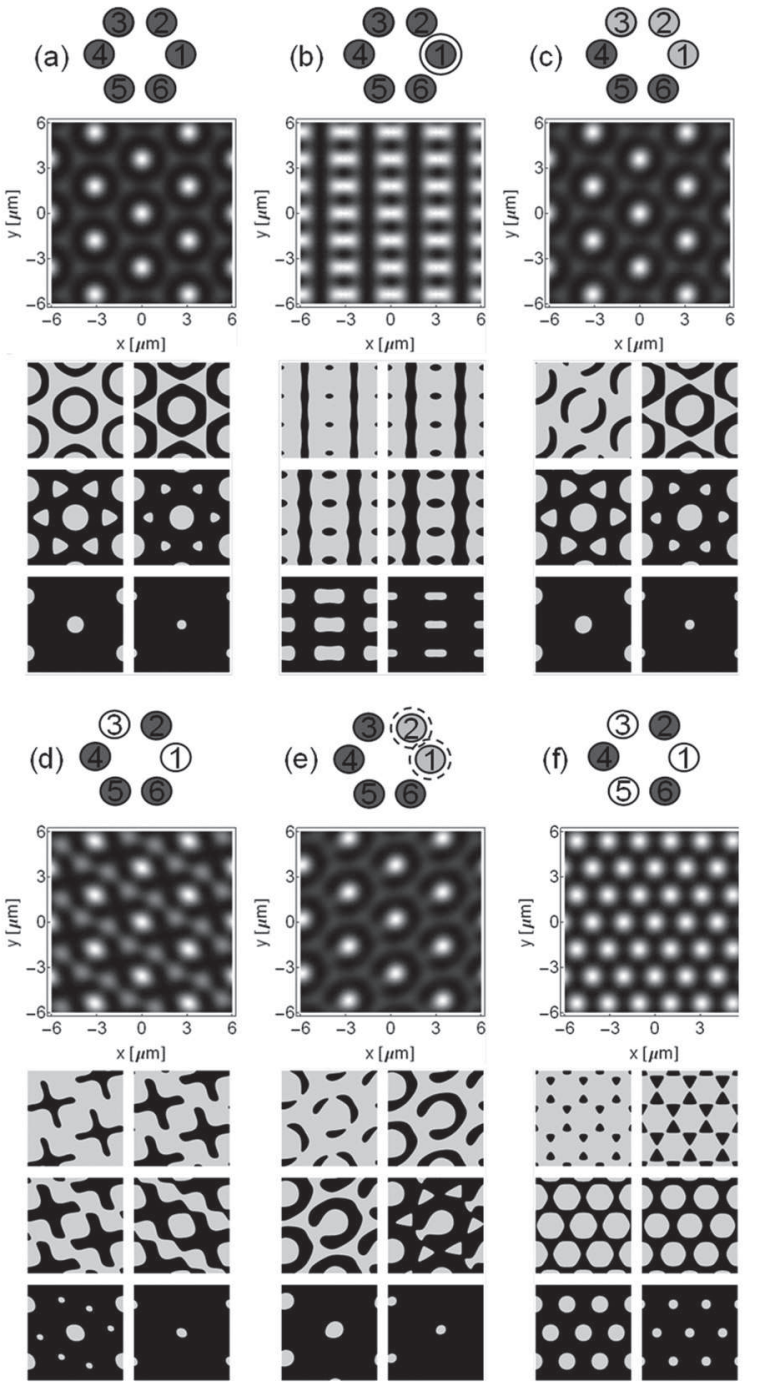

Fig. 3 Interference patterns of six beams at different parameters and ablation thresholds.

\section{4 基本波とSHGを同時照射する「モード同期干渉」 の場合の干渉パターン}

レーザーは非線形結晶を用いる事で半波長を持つSHG を発生させることができるが, これら2波長の位相差は 固定であり，分散制御技術と組み合わせることで実験に おいてコントロールすることも可能であり, 多波長用で 動作する透過型回折格子の研究も進んでいる. 本節で は，基本波及びSHGを同時に干渉させる技術をモード同 期干渉と名付け，その際の干渉パターンを示す。ここで は基本波及びSHGがそれぞれ4本，同じ光路を通って干 渉する場合について考える(Fig. 1 (a) (b)).

Fig. 4 (a) 及び(b) はそれぞれ基本波及びSHGの干渉パ ターン及びy=0に打けるクスセクションであり, 干 涉角以外はFig. 2 同様である. $E_{\text {fundamental }, n}=E_{S H G, n}$ とし た. Fig. 4 (c) は2波長を同時に干渉させた場合である。 最大ピーク強度を持つスポットの間隔は基本波のみの場 合と同じ約 $1.5 \mu \mathrm{m}$ となり, SHGのみの場合の倍である. 一方スポットサイズのFWHMは, 基本波とSHG単独で はそれぞれ約 $0.82 \mu \mathrm{m}$ と約 0.41 mであるのに対し約 $0.53 \mu \mathrm{m}$ となり，両波長の場合の中間に成った。これに
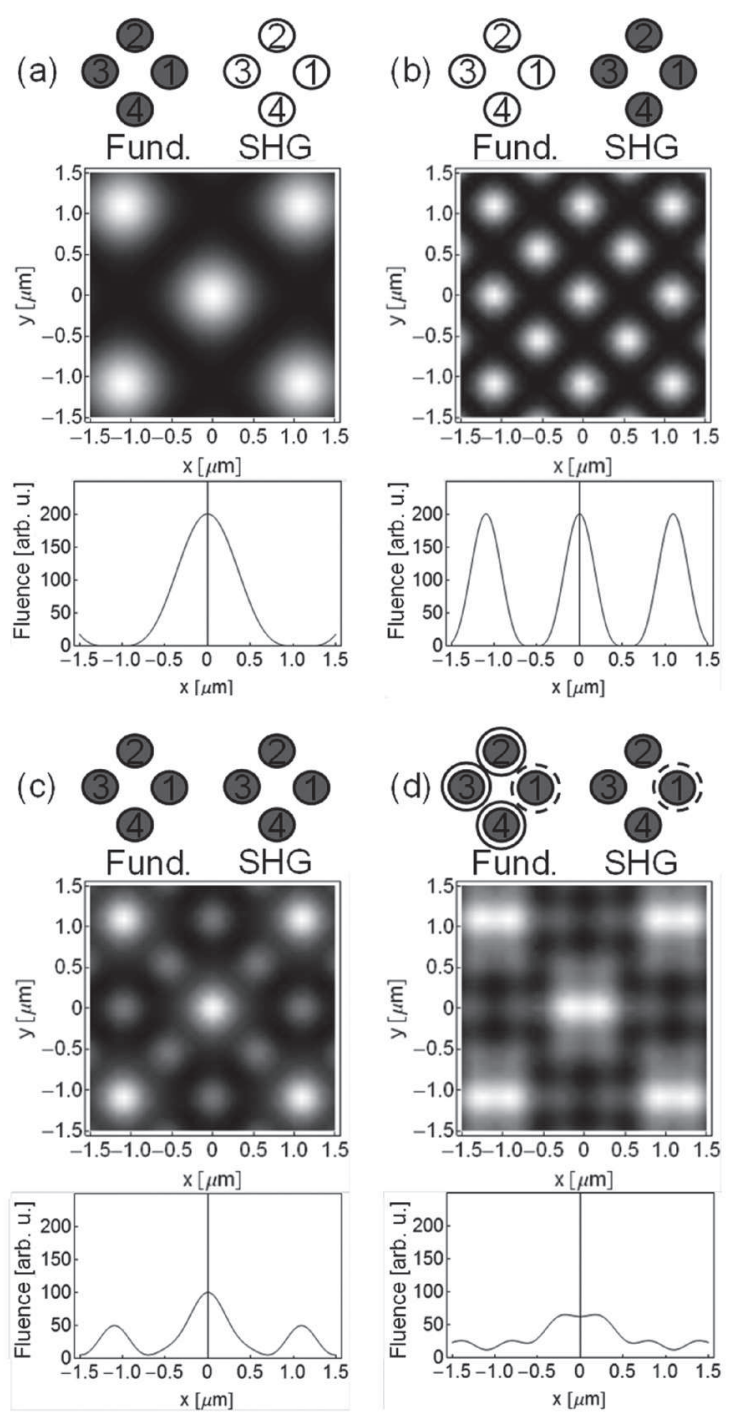

Fig. 4 Interference patterns of four fundamental and four SHG beams. (a) fundamental only, (b) SHG only, (c) fundamental and SHG, (d) (c) with phase shift between the beams.

より, 加工間隔を維持しつつ加工サイズを微細化するこ とが可能になった。ささらに位相差を加えたFig. 4 (d)の 場合では, ビット状の高フルエンス領域が周期配列して 㧍り，シングルショット加工によるメタマテリアル作製 に押けるパターンデザインの自由度が広がったと言える。

モード同期干渉によるスポットサイズの微細化及び干 渉パターンのデザインは従来にない新しい発想であり, メタマテリアルのみならず光量子科学分野全体に执いて 新しい応用を誘起する可能性があり, 詳細な調查を進め る予定である。

\section{SLSプロセスによって形成したナノウィスカー 構造のTEMを用いた測定}

前章で示した干渉パターンのデザインによる2次元周 期配列コントロールに対し，金属の流体的挙動を用いる SLSプロセスを用いる事で, 3次元ナノ構造が作製でき る。ここでは，SLSプロセスによって作製されたナノ 
(a)

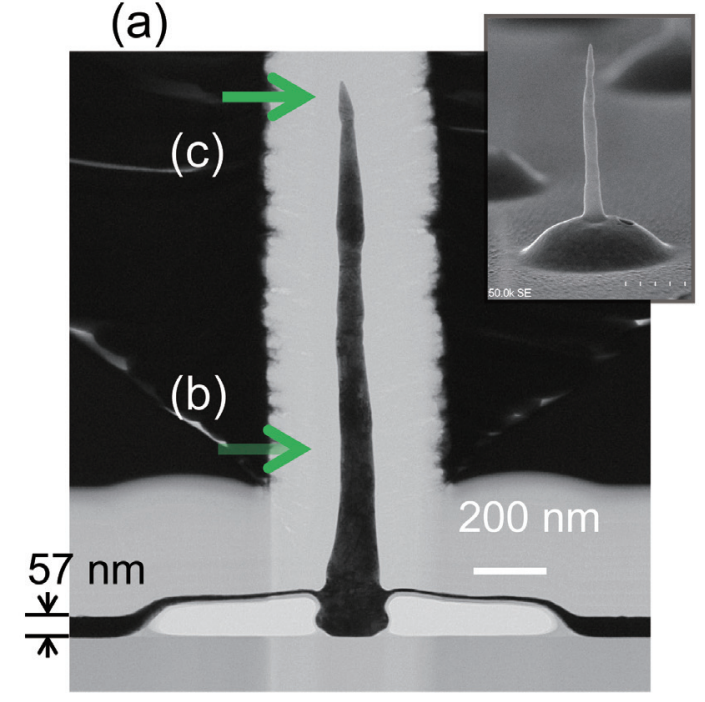

(b)

(c)
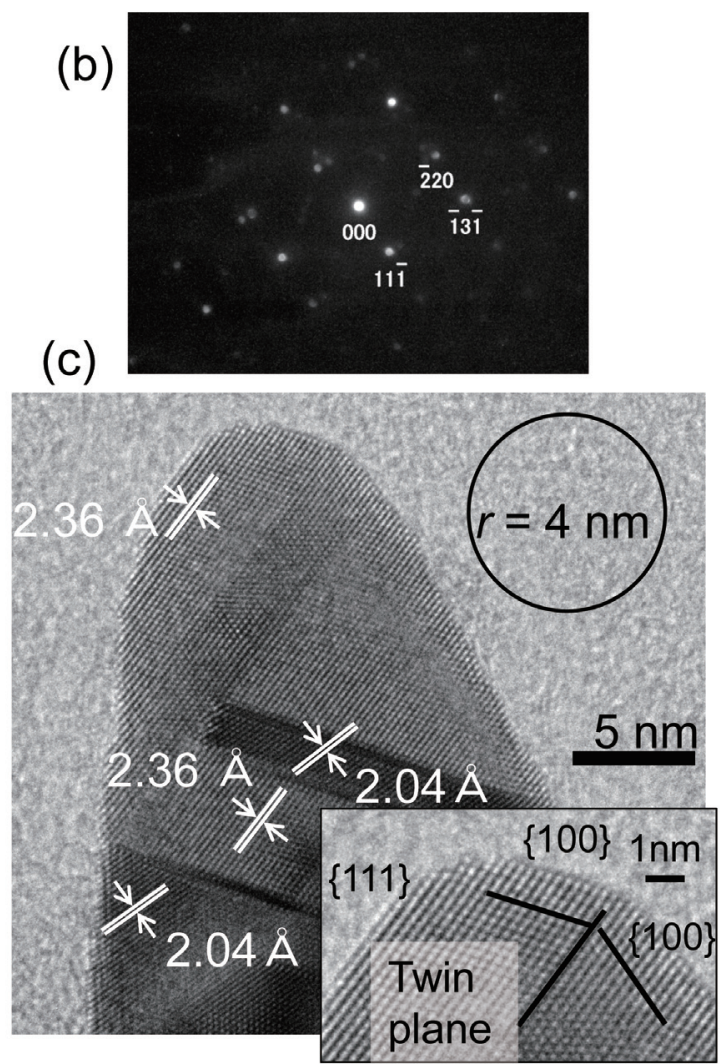

Fig. 5 TEM and SEM image of an Au nanowhisker. (a) whole view, (b) a selected area diffraction pattern at a point indicated in (a). (c) TEM image of the vertex and the magnified view.

ウイスカーの形状及び結晶構造をTEMで詳細に調べた 結果を紹介する，材料はシリカガラス基板に堆積した厚 さ57 $\mathrm{nm}$ の金薄膜であり，波長785 nm, パルス幅約 $140 \mathrm{fs}$, 平均フルエンス約 $136 \mathrm{~mJ} / \mathrm{cm}^{2}$ のレーザーで4光束 干渉加工を行うことでナノウイスカーを形成した。干渉 角は $\theta_{\text {int }}=14.6^{\circ}$, 干渉パターンの周期は $2.2 \mu \mathrm{m}$ である.

Fig. 5にTEMを用いた測定結果を示す ${ }^{12)}$. Fig. 5 (a)は 断面図であり, 右上のSEM像では見えないバンプ内部 が中空であることが確認された5) (同じナノウィスカー では無いため形状が若干異なることに注意)。バンプの 最も薄い部分は厚さ $7 \mathrm{~nm}$ であり，その中心にナノウィ
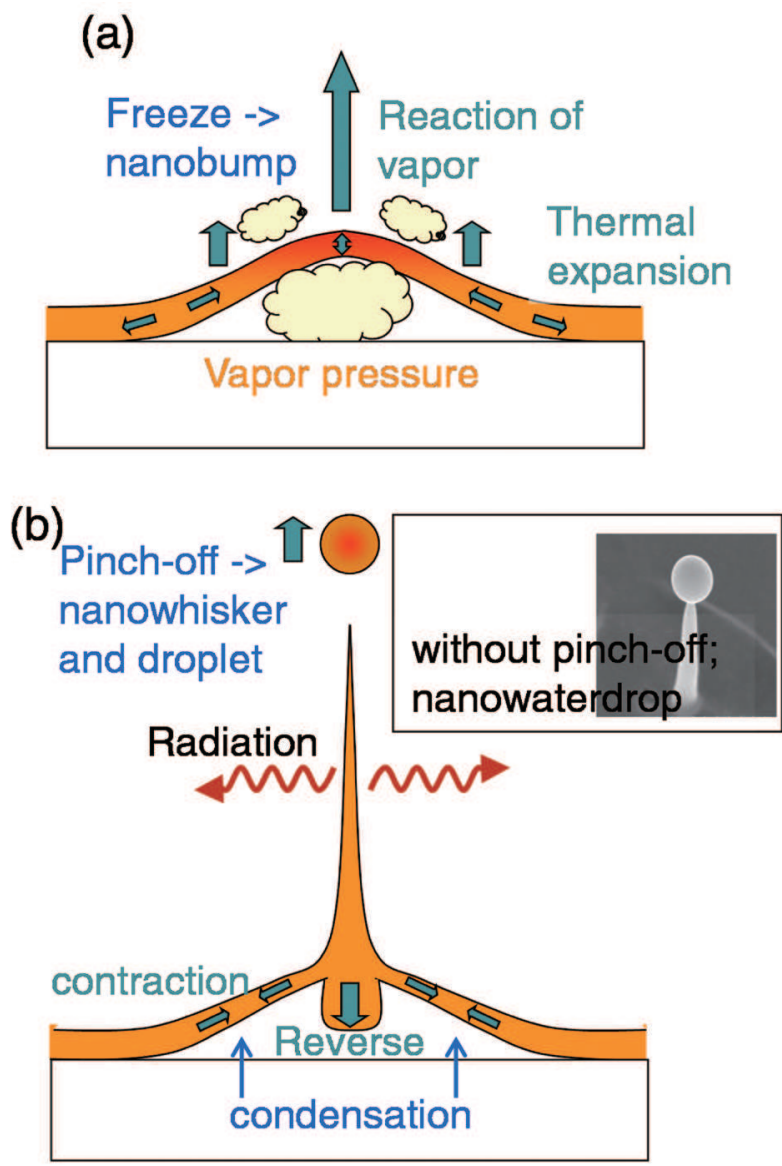

Fig. 6 Scheme of SLS process.

スカーが基板の上から直立している。 ナノウィスカー及 びバンプ領域の金の重量はそれぞれ0.21 pg, $0.49 \mathrm{pg}$ であ り，元の薄膜のほぼ半分が消失している。ここでナノ ウイスカー形成メカニズムであるSLSプロセスについ て, Fig. 6を用いて説明する。干渉パターンによって周 期的にエネルギーが注入され，フルエンスが高い部分で はFig. $6(\mathrm{a})$ のよう金薄膜が溶融・蒸発し, 蒸気圧や 熱膨張によって薄膜自体が持ち上がり, さらに温度が低

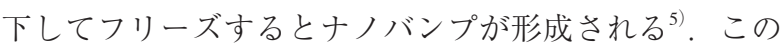
ように固体から流体的挙動を経て固化する一連のメカニ ズムをSLSプロセスと呼び，他のナノ構造形成メカニズ ムであるVLS (Vapor-Liquid-Solid) と区別する ${ }^{21)}$.フルエ ンスがさらに高い場合では, Fig. 6 (b)のように流体的 挙動と表面張力によってドロップレットが形成され，十 分な運動量と融点以上の温度があればターゲットから離 れ，残りの部分にナノウィスカーが形成される.

Fig. 5 (b) は (a)において矢印で示した部分のSAED (Selected-Area Electron Diffraction)であり，金のfcc(facecentered-cubic) 構造における(111)，（220），(131）面に由 来する回折が確認された. Fig. 5 (c) は頂点部分の拡大 図であり $\{111\} や\{200\}$ のファセットが確認された。 以上 から, ナノウイスカーは多結晶構造を持っていることが 解った。一般的にボトムアップ的手法では単結晶が出来 やすく, より高い強度を持つ多結晶構造が形成出来る意 味は大きい22)。図の右下は頂点部分の拡大図であり, ナ ノウィスカーの軸とファセットの方向が無関係であり, 
また双晶が出来ていることが解る。これらはボトムアッ プ的手法によるナノマテリアルと大きく異なる点であ る. 頂点の曲率半径は $4 \mathrm{~nm}$ であり, ボトムアップ的手 法で作製された最小ナノロッドの約半分まで微細化され ており ${ }^{23,24)}$ ，この点ではボトムアップ的手法を超えてい る。通常ボトムアップ的手法ではナノマテリアルがラン ダムな場所に形成され，凝集や融合する問題がある ${ }^{25)}$. 一方本手法ではナノウイスカーが離れて配列した状態で 形成されるため，そのような問題が無い.

\section{4. まとめ}

4光束及び6光束干渉において，ビーム間の位相及び強 度比を変調することによる干渉パターンの変化を調べ た. 前者は21パターン, 後者は32パターンに及ぶ自由度 が有り, さらに加工しきい值と加工フルエンスの関係を 利用することで干渉パターンを様々にデザイン出来るこ とが分かった。ささらに基本波とSHGを干渉させた場合 は，干渉パターンの周期を保ったままスポットサイズを 小さく出来る事が解った。 これらの多くはメタマテリア ルの形成にそのまま利用可能であり, また干渉条件は光 学技術を駆使することで実現可能である。マルチショッ 卜加工を行えば複合パターンや異種並列構造も作製で き，さらに多様化が可能である。また，トップダウン的 手法であるため多層膜やコンポジットがターゲットに利 用でき，ボトムアップ的手法には無い構造が形成出来 る。一方, SLSプロセスを誘起する加工条件ではナノ ウイスカーなどの3次元ナノ構造が作製できる，従来の ボトムアップ的手法の場合と異なる構造を持つ多結晶ナ ノウイスカーが正確に配列しており，特にメタマテリア ルやプラズモニクスへの応用が期待出来る. 本手法は全 く新しい手法であることから，ナノテクノロジー分野の 新しい手法や応用を誘起することが今後期待される。

謝 辞

本研究の一部は, 日本学術振興会・基盤研究 (B) (no.
$23360035)$ 及び文部科学省・新学術領域「電磁メタマテリ アル」(no. 23109509)の支援を受けて行われた。ここに謝 意を表する.

\section{参考文献}

1) K. O. Hill, Y. Fujii, D. C. Johnson, and B. S. Kawasaki: Appl. Phys. Lett. 32 (1978) 647.

2) C. V. Shank, J. E. Bjorkholm, and H. Kogelnik: Appl. Phys. Lett. 18 (1971) 395.

3) B. R. Brown and A. W. Lohmann: Appl. Opt. 9 (1966) 967.

4) Y. Qiu, L. Zhan, X. Hu, S. Luo, and Y. Xia: Display 32 (2011) 308.

5) Y. Nakata, T. Okada, and M. Maeda: Jpn. J. Appl. Phys. 42 (2003) L1452.

6) Y. Nakata, T. Okada, and M. Maeda: Appl. Phys. A 77 (2003) 399.

7) Y. Nakata, T. Okada, and M. Maeda: Appl. Phys. A 79 (2004) 1481.

8) Y. Nakata, N. Miyanaga, and T. Okada: Appl. Surf. Sci. 253 (2007) 6555.

9) Y. Nakata, T. Hiromoto, and N. Miyanaga: SPIE Newsroom, DOI:10.1117/2.1200906. 1708 (2009).

10) Y. Nakata, T. Hiromoto, and N. Miyanaga: Appl. Phys. A 10 (2010) 471.

11) Y. Nakata, K. Momoo, T. Hiromoto, and N. Miyanaga: Proc. SPIE 7920, DOI: $10.1117 / 12.881184$ (2011).

12) Y. Nakata, N. Miyanaga, K. Momoo, and T. Hiromoto: Appl. Surf. Sci. 274 (2013) 27.

13) Y. Nakata, K. Murakawa, K. Sonoda, K. Momoo, N. Miyanaga, and T. Hiromoto: Appl. Phys. A 112 (2012) 191

14) Y. Nakata, K. Murakawa, K. Sonoda, K. Momoo, and N. Miyanaga: Appl. Opt. 51 (2012) 5004.

15) I. I. Smolyaninov, Y. J. Hung, and C. C. Davis: Phys. Rev. B 76 (2007) 205424.

16) U. Huebner, J. Petschulat, E. Pshenay-Severin, A. Chipouline, T. Pertsch, C. Rockstuhl, and F. Lederer: Microelectronic Eng. 86 (2009) 1138.

17) B. Kang, E. Choi, H. H. Lee, E. S. Kim, J. H. Woo, J. Kim, T. Y. Hong, J. H. Kim, and J. W. Wu: Opt. Express. 18 (2010) 11552.

18) C. M. Soukoulis and M. Wegener: Nature. Photonics 5 (2011) 523.

19) W. K. Matthias, M. Wegener, N. Feth, and S. Linden: Opt. Express. 15 (2007) 5238.

20) D. P. Fromm, A. Sundaramurthy, A. Kinkhabwala, P. J. Schuck, G. S. Kino, and W. E. Moerner: J. Chem. Phys. 124 (2006) 061101.

21) R. S. Wagner and W. C. Ellis: Appl. Phys. Lett. 4 (1964) 89.

22) B. Wu, A. Heidelberg, and J. J. Boland: Nature Mat. 4 (2005) 525.

23) S. Link and M. A. El-Sayed: J. Phys. Chem. B 103 (1999) 8410.

24) C. J. Johnson, E. Dujardin, S. A. Davis, C. J. Murphy, and S. Mann: J. Mater. Chem. 12 (2002) 1765.

25) Y. Lu, J. Y. Huang, C. Wang, S. Sun, and J. Lou: Nature Nanotech. 5 (2010) 218. 